\title{
Two days with a broken knife blade in the neck - an interesting case of Horner's syndrome
}

\author{
S Dubois-Marshall, ${ }^{1}$ S De Kock ${ }^{2}$ \\ ${ }^{1}$ Breakthrough Breast Cancer Research Unit, Western General Hospital, Edinburgh, UK \\ ${ }^{2}$ Department of General Surgery, Ngwelezane Hospital, Empangeni, South Africa
}

Correspondence to S Dubois-Marshall, sylvie_dubois_marshall@hotmail.com

\section{Summary}

A 25-year-old man presented to the Emergency department in a rural South African hospital after a left, submental neck stab with a knife. Examination was deemed unremarkable, and the patient was discharged, but re-attended 2 days later complaining of a painful, swollen neck. Further examination identified Horner's syndrome, and further investigation revealed that the blade of the knife had remained in the patient's neck. This was successfully removed in theatre.

This case illustrates the importance of careful history, examination and diagnostic imaging in the management of penetrating neck injuries. Horner's syndrome can be easily missed in a busy Emergency department and may indicate life-threatening pathology in the context of neck trauma. The difficulties in assessing and managing this type of injury are discussed.

\section{BACKGROUND}

This is the first reported case of penetrating neck injury associated with Horner's syndrome with the foreign bodythe blade of a knife - remaining in situ. We discuss some of the difficulties in assessing and managing this type of injury.

\section{CASE PRESENTATION}

A 25-year-old African man attended the Emergency department in a rural South African hospital after a left, submental neck stab. Examination was deemed unremarkable, the wound was cleaned and sutured, and the patient discharged. The patient re-attended 2 days later complaining of a painful, swollen neck with some pussy discharge, but was otherwise well. An initial diagnosis of an abscess was made (figure 1), and the patient prepared for incision and drainage in theatre. A soft-tissue radiograph of the neck was requested by the anaesthetist who was concerned that intubation might be difficult. This revealed that the blade had remained in the patient's neck, and further examination of the patient revealed partial ptosis and meiosis on the side contralateral to the stab (figures 2, 3 and 4). This was associated with loss of sweating to the corresponding half of the face and mild clawing of the fingers of the right hand. Gastrograffin swallow was normal. The patient remained haemodynamically stable at all times with no hard signs of vascular injury.

\section{OUTCOME AND FOLLOW-UP}

The patient was taken to theatre where a percutaneous tracheostomy was performed for extensive swelling of the neck. The knife blade was removed via the entry site without further complication. The tracheostomy was removed on day 3 , and the patient was discharged home a few days later by which point there had been a slight improvement in his neurology. However, a residual ptosis and meiosis were still evident at 1-year follow-up.

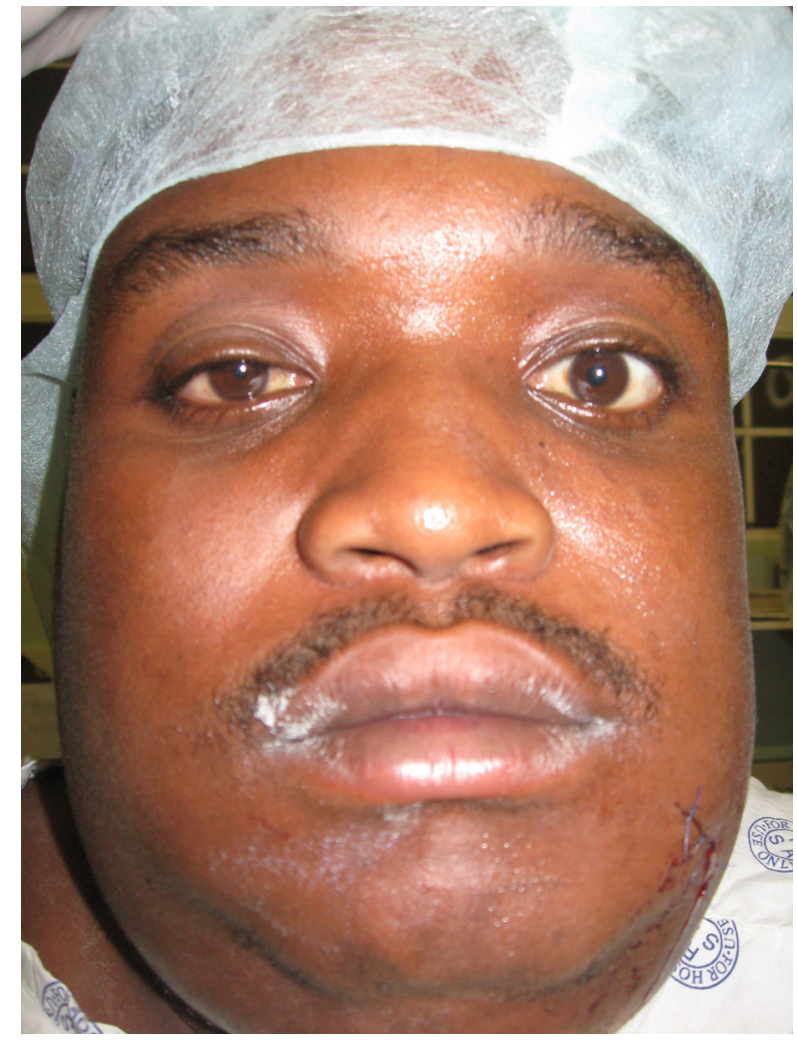

Figure 1 The original stab wound.

\section{DISCUSSION}

In fact, this patient exhibited the classic signs of Horner's syndrome: a loss of sympathetic innervation to the face from injury at various levels of the spinal cord or sympathetic chain. A basic understanding of the anatomy of the 


\section{BMJ Case Reports}

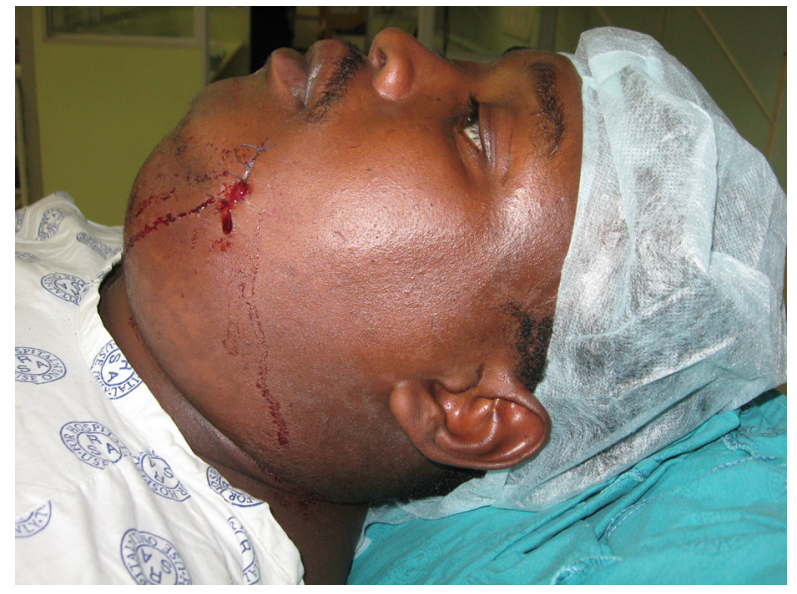

Figure 2 Right-sided Horner's syndrome is clearly demonstrated.

sympathetic division of the autonomic nervous system is required to understand the resulting signs. In the sympathetic division, cell bodies of preganglionic neurons are located in the lateral horn of the spinal cord (between the first thoracic level and the second or third lumbar level). These neurons send axons to paravertebral ganglia within the sympathetic chain. In the context of innervation to the head and neck, preganglionic fibres ascend to the superior cervical ganglion where they synapse onto postganglionic neurons. Axons from these neurons then innervate the head and neck. The clinical signs in this case consisted of partial ptosis (due to loss of sympathetic innervation to the levator palpebrae), meiosis (due to unopposed parasympathetic action on the sphincter papillae) and, as the lesion was below the superior sympathetic ganglion, anhydrosis. It remains unclear whether this case of Horner's was missed on first presentation or resulted from the blade remaining, and possibly moving, in the patient's neck over the 2-day period. Interestingly, this patient's transaxial stab was associated with a contralateral Horner's.

Horner's syndrome has multiple aetiologies, including malignant tumours (the most common cause) and benign tumours that are vascular, infectious, iatrogenic (including chest-drain insertion, central venous access, thyroidectomy and carotid angiography) and traumatic (including penetrating, blunt and birth related). Horner's has been previously described in the context of penetrating trauma, though isolated Horner's is uncommon. However, review of the literature suggests that this is the first reported case of a patient who presents with Horner's in the context of a penetrating neck injury with the foreign body still in situ.

The assessment and management of penetrating neck injuries is complex. The neck contains multiple structures in close proximity and surgical exploration can be difficult, requiring a thorough understanding of the relevant anatomy. There is no debate about the need to surgically explore a patient who is unstable or with hard signs of vascular injury. However, the management of patients with either no signs or 'soft' signs of clinical injury remains controversial. Some surgeons advocated mandatory exploration of all wounds penetrating the platysma, irrespective of signs and symptoms. They argue that physical signs are

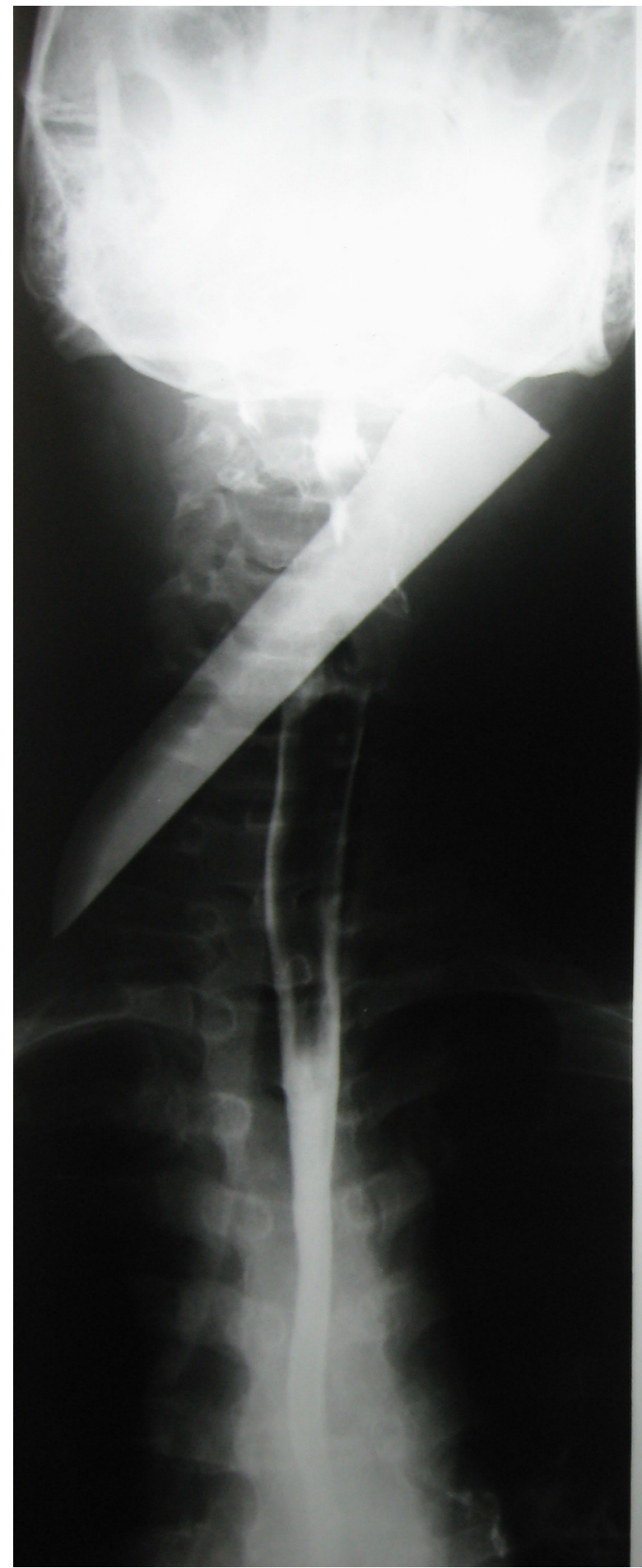

Figure 3 AP x-ray. Note the normal gastrograffin swallow.

unreliable and that morbidity from negative exploration is negligible and preferable to missed injury and its complications. This approach is associated with less invasive diagnostic studies (and consequently reduced costs) and short hospital stays. ${ }^{1}$ Nonetheless, this is also associated with a significant rate of negative explorations $(57 \%$ in the study described previously ${ }^{1}$ and higher in others), and recent evidence increasingly supports selective nonoperative management of penetrating neck injuries, relying on careful 


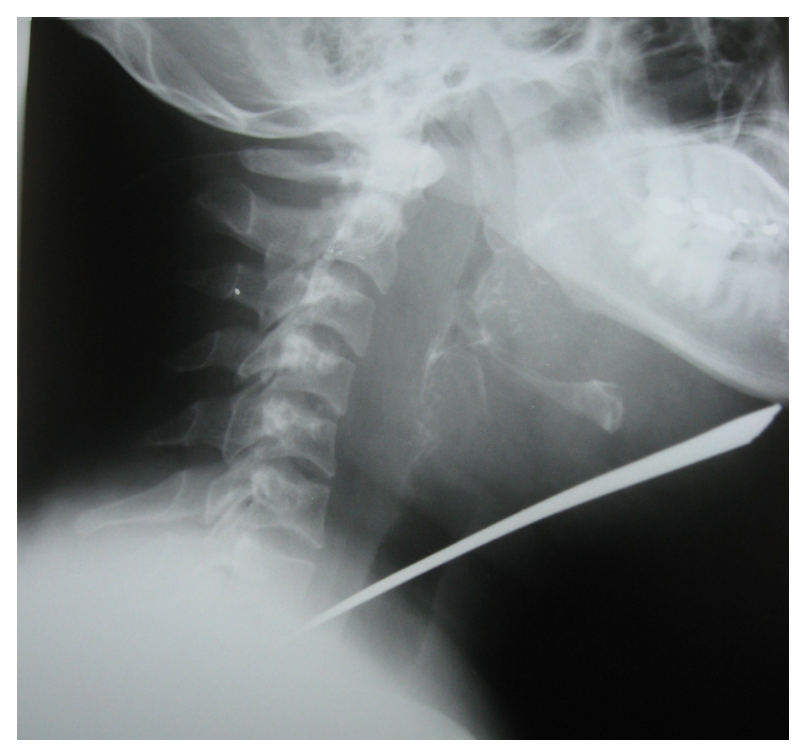

Figure 4 Lateral x-ray.

clinical examination and appropriate use of diagnostic imaging. ${ }^{2}$

It is important to remember that availability of diagnostic tools, costs and quality of follow-up are factors that are likely to influence a surgeon's approach to penetrating neck trauma. Thus, in some cases mandatory exploration may still be appropriate.

This case is clearly more complicated as the knife blade remained in situ. Two similar cases have been reported (neither with associated neurology). ${ }^{3}{ }^{4}$ Both used emergency CT angiography to exclude direct involvement of major vessels. In the case of a straight blade, this was easily removed via the entry site. ${ }^{3}$ In the more complicated case of a barbed spear, exploration was commenced via a median sternotomy to allow vascular control if required. The spear was then removed via the entry site while retracting major structures under direct vision. ${ }^{4}$

\section{Learning points}

- This case illustrates the importance of careful history, examination and diagnostic imaging in the management of penetrating neck injuries.

- Horner's syndrome can be easily missed in a busy Emergency department and may indicate lifethreatening pathology in the context of penetrating neck injuries.

-While this patient clearly required operative management, artefacts associated with preoperative CT angiography may have made this investigation inconclusive. Nonetheless, a postoperative CT angiograph should have been done to specifically exclude a vertebral artery injury.

\section{Competing interests None.}

Patient consent Obtained.

\section{REFERENCES}

1. Apffelstaedt JP, Mpller R. Results of mandatory exploration for penetrating neck trauma. World J Surg 1994;18:917-19.

2. Thoma M, Navsaria PH, Edu S, et al. Analysis of 203 patients with penetrating neck injuries. World J Surg 2008;32:2716-23.

3. Topalidis D, Cordera F, Kent MG, et al. Zone III penetrating neck trauma. Contemp Surg 2005;61:508-514

4. Cotton MH. Letter to the editor. World J Surg 1998;22:506.

\footnotetext{
This pdf has been created automatically from the final edited text and images.

Copyright 2010 BMJ Publishing Group. All rights reserved. For permission to reuse any of this content visit http://group.bmj.com/group/rights-licensing/permissions. BMJ Case Report Fellows may re-use this article for personal use and teaching without any further permission.

Please cite this article as follows (you will need to access the article online to obtain the date of publication).

Dubois-Marshall S, De Kock S. Two days with a broken knife blade in the neck - an interesting case of Horner's syndrome. BMJ Case Reports 2010; 10.1136/bcr.02.2010.2735, date of publication

Become a Fellow of BMJ Case Reports today and you can:

- Submit as many cases as you like

- Enjoy fast sympathetic peer review and rapid publication of accepted articles

- Access all the published articles

- Re-use any of the published material for personal use and teaching without further permission

For information on Institutional Fellowships contact consortiasales@bmjgroup.com

Visit casereports.bmj.com for more articles like this and to become a Fellow
} 